\title{
Validation and application of single breath-hold cine cardiac MR for ventricular function assessment in children with congenital heart disease at rest and during adenosine stress ${ }^{\#}$
}

\author{
ANDREW M. TAYLOR, M.D., M.R.C.P., F.R.C.R., ${ }^{1,3 * *}$ STEVEN DYMARKOWSKI, M.D., PH.D., ${ }^{1}$ KRISTOF DE MEERLEER, M.D., ${ }^{1}$ \\ PASCAL HAMAEKERS, R.N., ${ }^{1}$ MARC GEWILliG, M.D., PH.D., ${ }^{2}$ LUC MERTENS, M.D., PH.D., ${ }^{2}$ and JAN BOGAERT, M.D., PH.D. ${ }^{1}$ \\ ${ }^{1}$ Department of Radiology, Gasthuisberg University Hospital, Leuven, Belgium \\ ${ }^{2}$ Department of Pediatric Cardiology, Gasthuisberg University Hospital, Leuven, Belgium \\ ${ }^{3}$ Cardiothoracic Unit, Institute of Child Health and Great Ormond Street Hospital for Children, London, UK
}

\begin{abstract}
Purpose. To validate the accuracy of ventricular function analysis using a single breath-hold real-time steady sate free precession (SSFP) cine MR method and demonstrate its application during adenosine stress imaging in children with congenital heart disease. Materials and Methods. Twenty-eight subjects with congenital heart disease were studied (mean age $12.4 \pm 2.3$ years) with MR imaging at 1.5 T. Shortaxis images covering the entirety of both ventricles were acquired at rest, with a conventional segmented SSFP cine sequence acquired over multiple breath-holds and a single breath-hold real-time SSFP sequence. Seventeen subjects were given an infusion of adenosine, and the single breath-hold real-time short-axis stack was repeated during stress. Two independent observers performed the ventricular function analysis. Data was compared between the 2 acquisition methods at rest and between the single breath-hold acquisition at rest and during adenosine stress. Results. There was good agreement between the multiple breath-hold and single breath-hold methods for measurement of end-diastolic volume $(\mathrm{r}=0.95$ and $0.96, \mathrm{p}<.0001)$ and end-systolic volume (ESV) $(\mathrm{r}=0.76$ and $0.90, \mathrm{p}<.0001)$ for the left and right ventricles respectively, and the left ventricular mass $(\mathrm{r}=0.97, \mathrm{p}<.0001)$. Adenosine was administered safely to all subjects. During stress there were significant changes in the heart rate and ESV, which led to a significant increase in cardiac output (mean $1.5 \pm 1.0 \mathrm{~L} / \mathrm{min}$, $\mathrm{p}<.001)$. Conclusion. Single breath-hold real-time SSFP cine imaging is robust and accurate in assessing cardiac function in children with congenital heart disease. An application of this method is the rapid assessment of cardiac function during adenosine stress.
\end{abstract}

Key Words: Congenital heart disease; Ventricular function; Adenosine stress

\section{Introduction}

Cardiac MR is now well established as one of the first line investigations for imaging older children and adults with congenital heart disease (1). More recently, there has been an increase in the number of younger children undergoing cardiac MR $(2,3)$. Cardiac MR can often give complimentary information to echocardiography. In particular, cardiac MR can provide accurate quantitative cardiac function data (right

Received 11 January 2005; accepted 25 May 2005.

${ }^{\#}$ Dr. Andrew M. Taylor, M.D., M.R.C.P., F.R.C.R., is supported by the Higher Education Funding Council of England (HEFCE) and in part by a Marie-Curie Fellowship of the European Commission. This research was supported in part by a grant from the Belgian Foundation for Research in Paediatric Cardiology. Luc Mertens, M.D., is a clinical researcher for the Fund for Scientific Research (FWO).

*Address correspondence to Dr. Andrew M. Taylor, M.D., M.R.C.P., F.R.C.R., Cardiothoracic Unit, Great Ormond Street Hospital for Children, Great Ormond St., London WC1N 3JH, UK; Fax: +44-(0)-207-813-8263; E-mail: a.taylor@ich.ucl.ac.uk and left ventricular volumes, mass and function) and is now regarded as the best available in-vivo method for measuring these parameters in adults $(4,5)$.

The major limitations for cardiac MR in young children are the need to remain relatively still within the scanner for up to an hour and the need for breath-holding to acquire images without respiratory artifacts. For most children under the age of 7 , sedation or at time general anesthesia is necessary, and this must be taken into account when planning investigations.

Cardiac MR function measurements are made by tracing endo- and epicardial borders during end-diastole and endsystole on a stack of short-axis images that cover the entire heart in the short axis plane. In most institutions, these images are acquired over multiple breath-holds, with one short axis slices acquired per breath-hold, and 8-12 consecutive breathholds performed to acquire the entire data-set. However, for young children who can be scanned without anesthesia, breath holding remains problematic $(6,7)$, and a method of acquiring an entire ventricular data set in a single breath-hold would be useful. This would restrict the number of breathholds required to a minimum and limit the effects of misregistration between multiple breath-holds. 
A possible application of acquiring data in a single breathhold would be to assess cardiac function during pharmacological or physiological stress (8) or during simultaneous ventricular pressure monitoring (9). During stress, performing multiple breath-holds is both difficult for the patient and timeconsuming for the operator. Furthermore, using a single breath-hold technique, data would be acquired at one short time-point when stress parameters are relatively fixed and not over several time-points where the effects of stress may vary over time.

The aim of this study was two-fold:

1. To validate the accuracy of ventricular volume and mass measurements made with a commercially available singleshot, real-time steady state free precession (SSFP) cine MR sequence acquired over a single breath-hold, against a more conventional, segmented SSFP sequence acquired over multiple breath-holds.

2. To demonstrate the application of the single breath-hold method during adenosine stress in children with congenital heart disease.

\section{Materials and methods}

\subsection{Study population}

Twenty-eight consecutive subjects with congenital heart disease were studied (mean age $12.4 \pm 2.3$ years, range 8.8-16.8 years, 12 female, 16 male). Seventeen subjects had congenital aortic stenosis, and 11 subjects had transposition of the great arteries (repaired with arterial switch operation). In addition to recruitment to the study of this manuscript, the subjects with aortic stensosis were recruited to assess myocardial perfusion, and the subjects with transposition of the great arteries were recruited to assess coronary artery anatomy (10). Seventeen subjects were given an infusion of adenosine $0.14 \mathrm{mg} / \mathrm{kg} / \mathrm{min}$ over 6 minutes (mean age $13.2 \pm 2.6$ years, range $8.8-16.8$ years, 6 female, 11 male, 15 congenital aortic stenosis, 2 repaired transposition of the great arteries). Two subjects with congenital aortic stenosis were not given adenosine because of contraindications to this agent. For the two subjects with transposition of the great arteries, adenosine was administered in order to assess myocardial perfusion to assess possible coronary artery stenosis. All studies were performed in accordance with the guidelines of the hospital committee on medical ethics and clinical investigation. Informed consent was obtained from all patients and/or their parents/guardians.

\subsection{MR imaging}

All images were obtained with a $1.5 \mathrm{~T}$ MR scanner (Philips Medical Systems, Best, The Netherlands) equipped with Master gradients (amplitude $30 \mathrm{mT} / \mathrm{m}$, slew rate $150 \mathrm{mT} / \mathrm{m} / \mathrm{s}$ ), using a dedicated cardiac software package on Release 9. A standard 5-element Synergy cardiac coil and VectorCardioGram (VCG) (Philips Medical Systems, Best, The Netherlands) cardiac triggering were used. All subjects were examined in the supine position with the VCG-leads on the anterior left hemi-thorax.

For all scans, a local shim volume was positioned over the heart to optimize the magnetic field homogeneity in this region.

A survey was initially acquired in the transverse, coronal and sagittal planes. A SENSE reference scan was then performed $(11,12)$. Axial breath-hold balanced fast-fieldecho anatomical images through the heart and great vessels were acquired. Vertical long axis and horizontal long axis cine balanced turbo-field-echo (TFE) images were then acquired and the short axis (SA) plane prescribed off both these images. Short axis images were acquired from the base of the heart (aligned parallel to the $\mathrm{AV}$ valves in diastole) to the apex, encompassing the entirety of both ventricles. The SA stack was repeated for both a conventional segmented 2D balanced TFE sequence acquired over multiple breath-holds (TR $3.8 \mathrm{~ms}$, TE $1.9 \mathrm{~ms}$, flip angle $60^{\circ}$, slice thickness $7 \mathrm{~mm}$, matrix $160 \times 256$, field of view $300 \mathrm{~mm}$, phases 30 , SENSE factor 1), and a real-time balanced TFE sequence acquired during a single breath-hold (TR $2.8 \mathrm{~ms}$, TE $1.4 \mathrm{~ms}$, flip angle $60^{\circ}$, slice thickness $10 \mathrm{~mm}$, matrix $122 \times 256$, field of view $350 \mathrm{~mm}, 20$ phases presented using echo sharing, SENSE factor 2). The reduction in acquisition time to enable 20 frames per cardiac is achieved by using a combination of parallel imaging (SENSE factor 2) and echo sharing, with $k$-space lines shared to the extent that the entire R-R interval is divided into 20 equal parts. In this later sequence, k-space was filled in a single-shot, with acquisition of all the data for one slice during one R-R interval. This differs from the conventional segmented $2 \mathrm{D}$ sequence, where each image was composed of k-space lines acquired over several R-R intervals. Both sequences were retrospectively gated. For the single-shot method, this results in retrospective reordering of the acquired real-time images into the R-R interval over which they were acquired. The images can thus be accepted by post-processing software as dynamic cardiac studies and can be further analyzed: an advantage over non-triggered real time scans (13).

For the 17 subjects who were given an infusion of adenosine, the single breath-hold real-time balanced TFE SA stack was repeated during adenosine infusion (5 minutes after commencement of adenosine infusion).

\subsection{MR imaging analysis}

Two independent observers performed the ventricular volume, mass and function assessment. Analysis was performed using EasyVision (Philips Medical Systems, Best, The Netherlands). End-diastole and end-systole were selected, and the endocardial ventricular contours traced for each slice at both time points. This was performed for both the right 


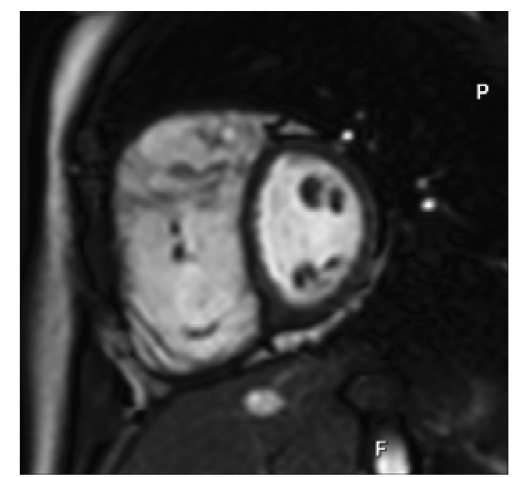

a

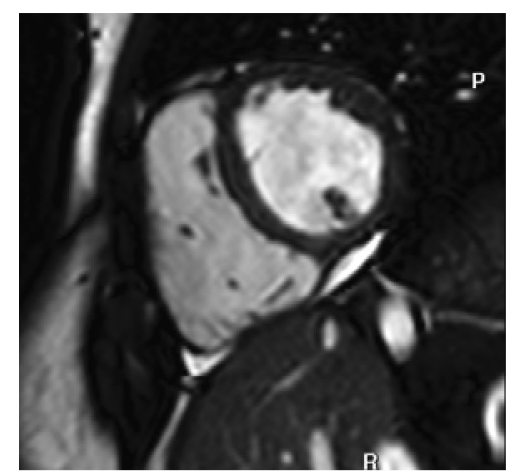

C

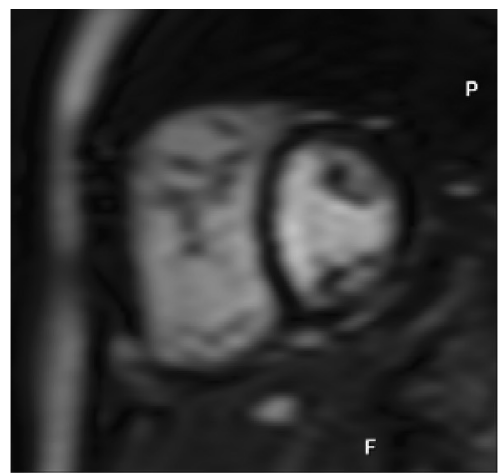

$\mathrm{b}$

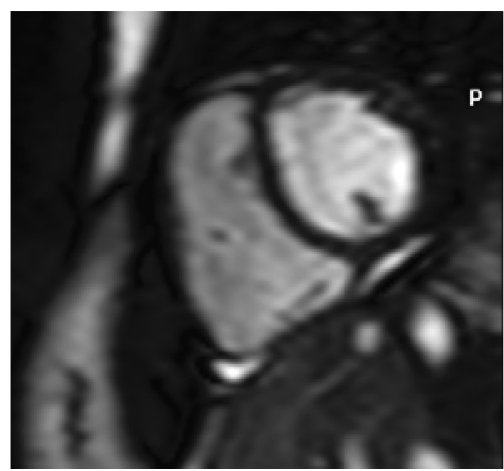

d

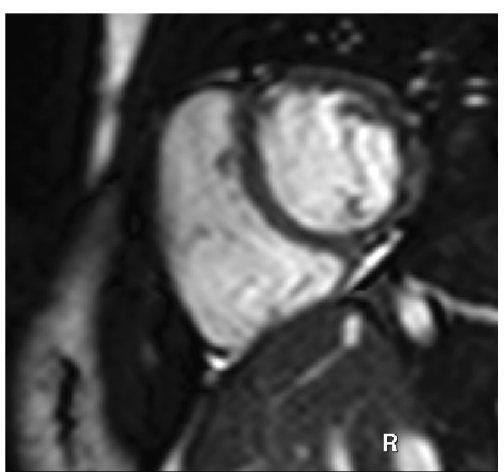

Figure 1. Two patient examples of image quality. Diastolic mid-ventricular short axis frame; multiple breath-hold method at rest (a and c), single breath-hold method at rest ( $b$ and $d)$, and single breath-hold method during adenosine stress (e).

(RV) and left ventricles (LV). The LV epicardial border was also drawn on the systolic slices. The RV and LV end-diastolic volume (EDV), end-systolic volume (ESV), stroke volume (SV), ejection fraction (EF), cardiac output (CO) and left ventricular mass were calculated for all patients at rest for both methods and during adenosine stress for the single breath-hold real-time method. All measurements were corrected for body surface area. The SA stacks were presented to both observers in random order.

Total image acquisition time was measured for both the multiple breath-hold and single breath-hold methods.

\subsection{Statistical analysis}

Data are expressed as the mean \pm standard deviation. Correlation coefficients and Bland Altman analysis were used to compare the two methods of measuring ventricular volumes, mass and function at rest. Bias was the mean of the difference between the two methods and agreement was the mean \pm 2 standard deviations (14).

The paired student $t$-test was performed to compare the acquisition times between the two methods at rest, and the ventricular volume, mass and function data measured at rest and during adenosine stress with the single breath-hold method.

Statistical analysis was performed using Matlab (Mathsworks Inc., Natick, MA, USA) and SPSS version 12 (SPSS
Inc., Chicago, IL, USA). A p value of $<.05$ was taken as statistically significant.

\section{Results}

\subsection{Accuracy of single breath-hold cardiac function measurements}

Ventricular volume, mass and function analysis was possible on all images acquired with the single breath-hold real-time method (Fig. 1).

There was good agreement between the multiple breathhold and single breath-hold methods for measurement of the $\operatorname{EDV}(\mathrm{r}=0.95$ and $0.96, \mathrm{p}<0.0001)$ and end-systolic volume $(\mathrm{ESV})(\mathrm{r}=0.76$ and $0.90, \mathrm{p}<.0001)$ for the left (Fig. 2) and right ventricles (Fig. 3) respectively, and the left ventricular mass $(r=0.97, p<.0001$, Fig. $4 d)$ (Table 1). There was a small systematic overestimate of the volume measurements by the single breath-hold method and a corresponding underestimate of the LV mass (Table 1). This led to a reduced ejection fraction calculation, but no significant bias in the cardiac output calculation (Table 1).

In all subjects in whom there was no evidence of valvular incompetence, the right and left ventricular stroke volumes 
a) LV EDV multiple BH vs. single BH
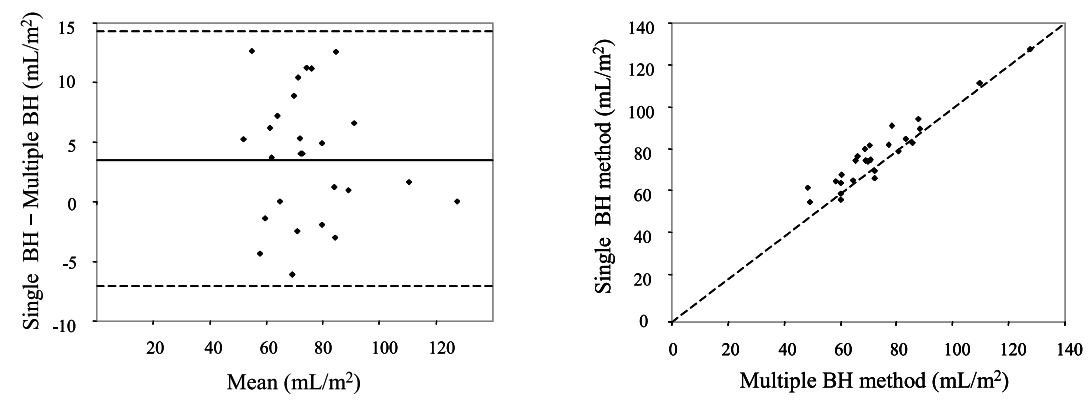

b) LV ESV multiple BH vs. single BH
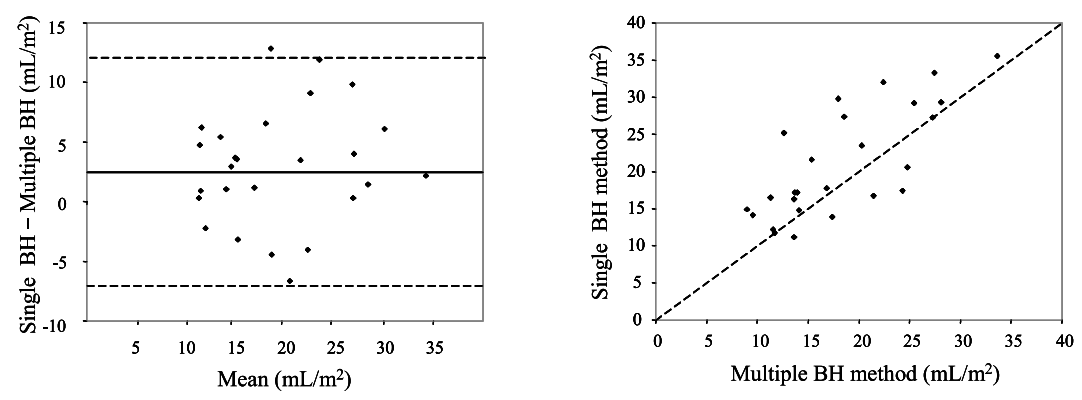

c) LV CO multiple BH vs. single BH
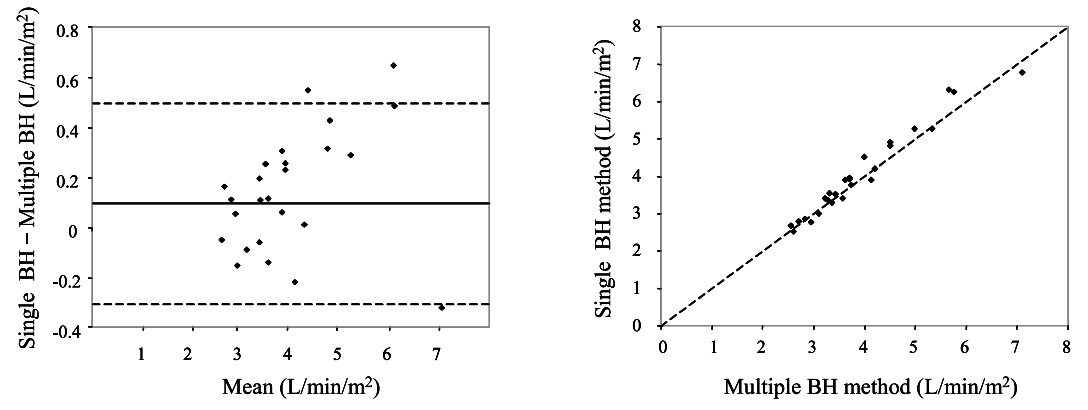

d) LV mass multiple $\mathrm{BH}$ vs. single $\mathrm{BH}$
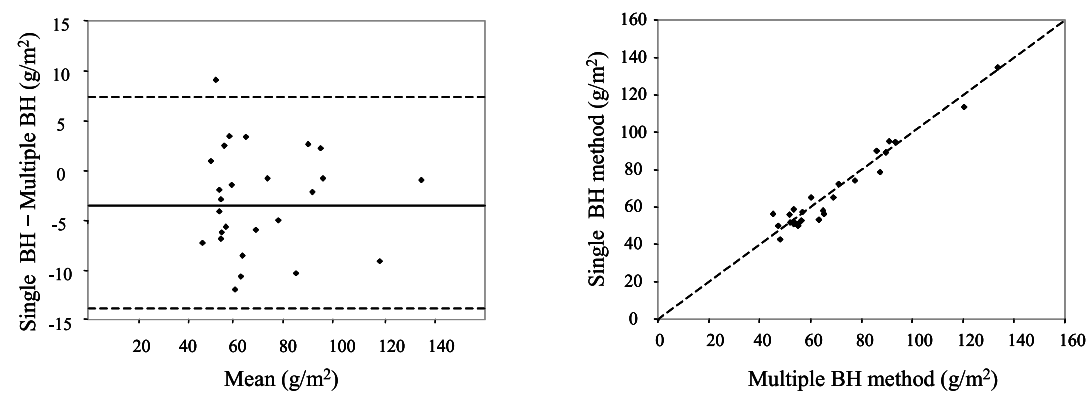

Figure 2. Bland-Altman and scatter plots for left ventricular measurements. On the scatter plots, the dotted line represents line of equality. LV—left ventricle, EDV—end-diastolic volume, ESV—end-systolic volume, CO—cardiac output.

were compared with good agreement; $r=0.97$ for multiple breath-hold method, and $\mathrm{r}=0.90$ for the single breath-hold method (both $\mathrm{p}<.0001$ ) (Table 2).

There was good agreement between the two observers for the assessment of the measured left ventricular parameters
(EDV, ESV, LV mass) for the multiple breath-hold and single breath-hold methods at rest (Table $3 \mathrm{a}$ and $\mathrm{b}$ ).

In two patients who could not breath-hold appropriately, the multiple breath-hold technique images were not interpretable, while the single breath-hold images (not actually 
a) RV EDV multiple $\mathrm{BH}$ vs. single $\mathrm{BH}$
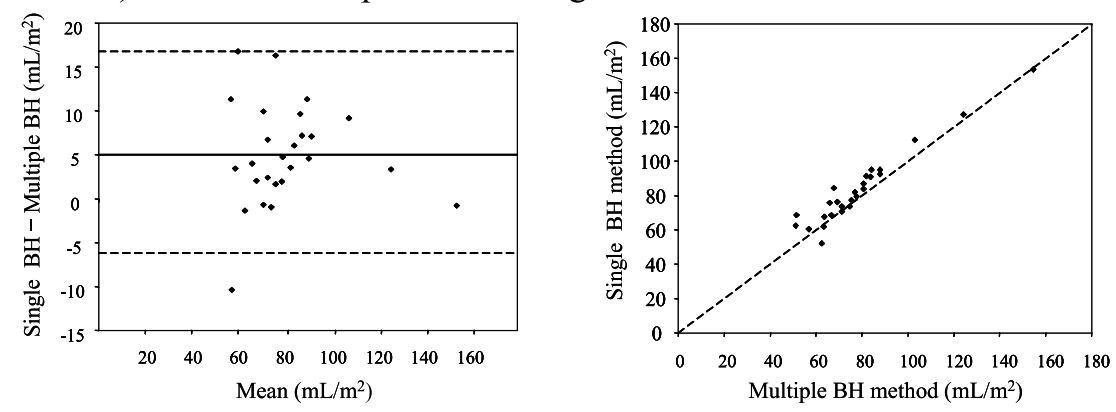

b) RV ESV multiple BH vs. single BH
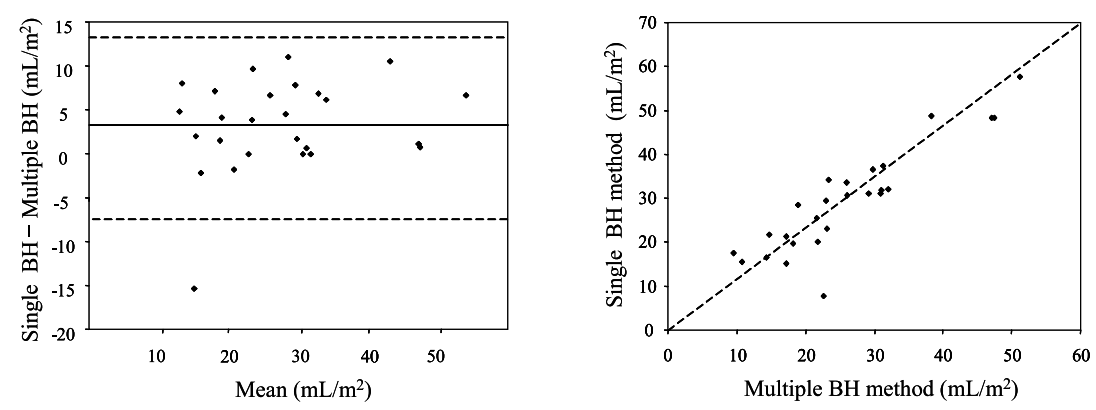

c) RV CO multiple BH vs. single BH
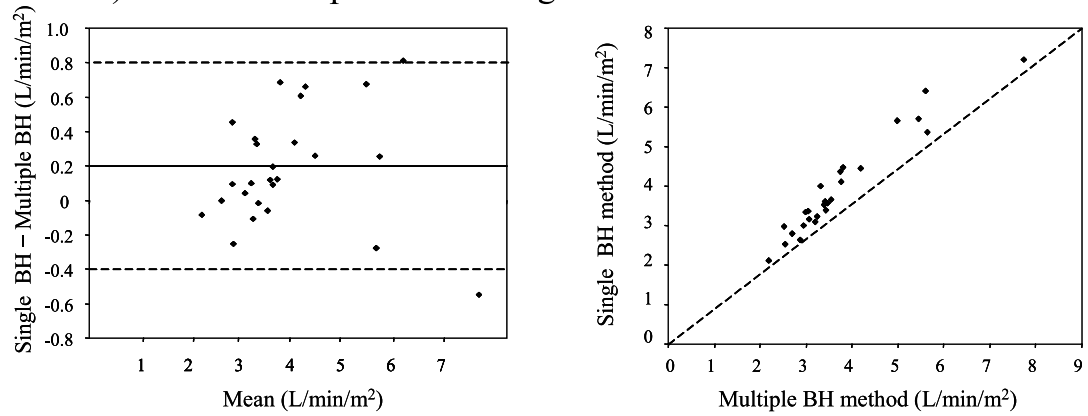

Figure 3. Bland-Altman and scatter plots for right ventricular measurements. On the scatter plots, the dotted line represents line of equality. RV—right ventricle, EDV—end-diastolic volume, ESV—end-systolic volume, CO — cardiac output.

acquired during breath-holding) were of good quality and useable for cardiac function analysis.

The total acquisition time for the single breath-hold method $(13.9 \pm 2.8 \mathrm{~s}$, range $8.4-18.5 \mathrm{~s})$ was significantly less than the multiple breath-hold method $(84.5 \pm 13.7 \mathrm{~s}$, range $38-127$, $\mathrm{p}<.001)$. Note, the multiple breath-hold time was the data acquisition time only and does not include the rest time between breath-holds.

\subsection{Effects of adenosine stress on cardiac function}

Adenosine was administered safely to all subjects with no major side effects.

Image quality remained good, and ventricular volume analysis was possible on all images acquired with the single breath-hold real-time method (Fig. 1e). There was good agreement between the two observers for the assessment of the measured left ventricular parameters for the single breathhold methods during stress (Table $3 \mathrm{c}$ ).

During adenosine stress there was a significant increase in the heart rate $(p<.001)$. Furthermore, there was significant change in all the left and right ventricular parameters (reduced ESV, increased SV, increased EF and increased cardiac output) except for the EDV, which showed a small non-significant increase (Table 4). There was no correlation between the percentage change in heart rate and the percentage change in stroke volume $(r=0.06, p=.9)$. Cardiac output increased in all patients (mean increase $1.5 \pm 1.0 \mathrm{~L} / \mathrm{min}$, range $0.1-2.9$, $\mathrm{p}<.001$ ) (Figure 4).

\section{Discussion}

In our own practice, children less than 7 years of age, with an absolute indication for cardiac MR, are imaged under general 


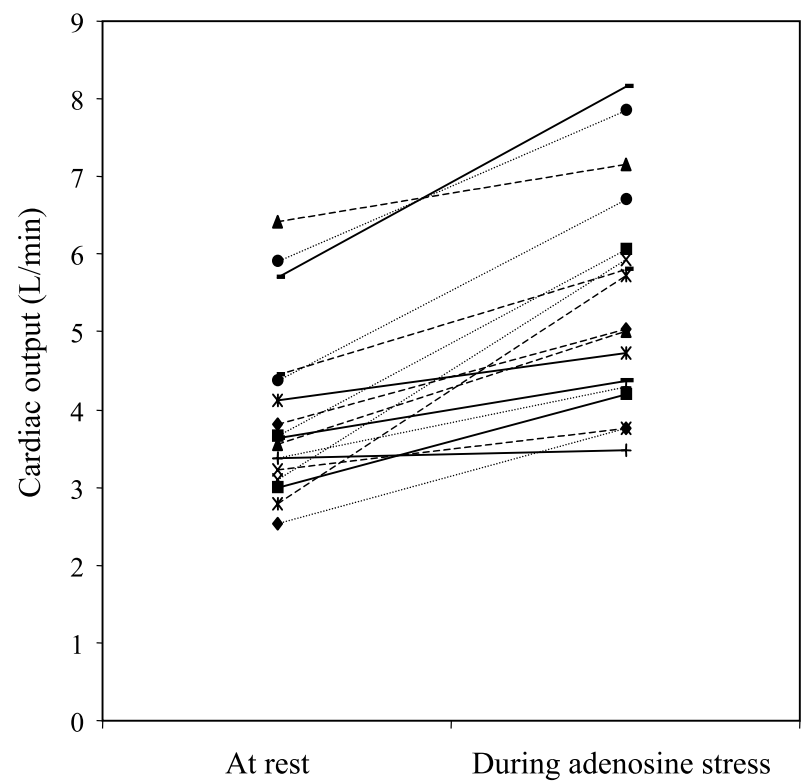

Figure 4. Changes in cardiac output measured during adenosine stress.

anesthesia. In these children, respiratory motion is reduced during image acquisition by brief cessation of ventilation under anesthetist control. In older children ( $8-16$ years), imaging is performed without general anesthesia, and breath holding is required to ensure reduction of respiratory artefacts during data acquisition. However, breath holding is problematic with several problems, which are well documented in adults $(6,7)$, but are probably more of an issue in children. These include: an inability to understand and follow the instructions for breath-holding; an inability to maintain a breath-hold for the whole scan (15-20 s); and an inability to maintain the same breath-hold position over multiple breathhold, leading to errors of mis-registration.

For cardiac ventricular volumes, mass and function assessment, acquisition of data in the short axis plane, over several breath holds is necessary for current gradient echo $(4,5)$ or steady steady state free precession sequences $(15,16)$. In adolescents and adults who are able to breath-hold well, this can be achieved in 4-6 breath-holds (sufficient time to acquire two short axis cine images per breath-hold). However, for most children, $8-12$ breath-holds would be the norm (one short axis cine image per breath-hold).

\subsection{Accuracy of single breath-hold real-time ventricular analysis}

In this study, we have demonstrated that a commercially available single breath-hold real-time cine MR method can give an accurate, robust assessment of cardiac function in the routine clinical investigation of children with congenital heart disease. There was good agreement between the conventional multiple breath-hold and the single breath-hold real-time methods for measurement of cardiac volumes, mass and function.

Interestingly, in two patients who could not breath-hold appropriately, the multiple breath-hold images were uninterpretable, while the single breath-hold real-time images (not actually acquired during breath-holding) were of good quality and useable for cardiac function analysis. This reflects the fact that in the single breath-hold method, a single short axis slice is acquired during one heartbeat, and each phase within the data set in one-tenth of this period is insufficient time for the images to be degraded by respiratory motion.

There were some differences between the two methods for the assessment of ventricular indices, and these should be borne in mind when interpreting real-time ventricular studies. The Bland-Altman comparison between the two methods demonstrated a small systematic bias, with higher enddiastolic and end-systolic volumes measured by the single breath-hold method. This leads to similar stroke volume calculations, but an underestimation of the ejection fraction as compared with the multiple breath-hold method. At

Table 1. Comparison data for ventricular volumes, mass and function between the multiple breath-hold (BH) and single BH balanced TFE sequences $(\mathrm{n}=28)$

\begin{tabular}{|c|c|c|c|c|c|}
\hline \multirow[b]{2}{*}{ Parameter } & \multirow[b]{2}{*}{ Multiple BH Balanced FFE } & \multirow[b]{2}{*}{ Single BH Balanced FFE } & \multicolumn{3}{|c|}{ Absolute differences } \\
\hline & & & Mean & SD & $\mathrm{r}$ value \\
\hline $\operatorname{LV} \operatorname{EDV}\left(\mathrm{mL} / \mathrm{m}^{2}\right)$ & $73 \pm 17$ & $77 \pm 17$ & 3.8 & 5.4 & $0.95^{*}$ \\
\hline $\operatorname{LV} \operatorname{ESV}\left(\mathrm{mL} / \mathrm{m}^{2}\right)$ & $18 \pm 7$ & $21 \pm 7$ & 2.7 & 4.9 & $0.76^{*}$ \\
\hline $\operatorname{LV~SV~}\left(\mathrm{mL} / \mathrm{m}^{2}\right)$ & $55 \pm 14$ & $56 \pm 14$ & 1.1 & 3.3 & $0.97 *$ \\
\hline LV EF (\%) & $75 \pm 7$ & $73 \pm 8$ & -2.4 & 5.3 & $0.75^{*}$ \\
\hline $\operatorname{LV} \mathrm{CO}\left(\mathrm{L} / \mathrm{m}^{2}\right)$ & $3.9 \pm 1.1$ & $4.0 \pm 1.2$ & 0.1 & 0.2 & $0.98^{*}$ \\
\hline LV mass $\left(\mathrm{g} / \mathrm{m}^{2}\right)$ & $70 \pm 22$ & $67 \pm 22$ & -3.1 & 5.2 & $0.97 *$ \\
\hline $\operatorname{RV} \operatorname{EDV}\left(\mathrm{mL} / \mathrm{m}^{2}\right)$ & $78 \pm 22$ & $83 \pm 22$ & 5.0 & 5.8 & $0.96^{*}$ \\
\hline $\operatorname{RV} \operatorname{ESV}\left(\mathrm{mL} / \mathrm{m}^{2}\right)$ & $26 \pm 11$ & $29 \pm 12$ & 3.3 & 5.2 & $0.90 *$ \\
\hline $\operatorname{RV} \mathrm{SV}\left(\mathrm{mL} / \mathrm{m}^{2}\right)$ & $52 \pm 15$ & $54 \pm 13$ & 1.7 & 4.0 & $0.96^{*}$ \\
\hline RV EF (\%) & $67 \pm 9$ & $65 \pm 9$ & -1.7 & 5.9 & $0.77 *$ \\
\hline $\mathrm{RV} C \mathrm{CO}\left(\mathrm{L} / \mathrm{m}^{2}\right)$ & $3.7 \pm 1.2$ & $3.9 \pm 1.2$ & 0.2 & 0.3 & $0.96^{*}$ \\
\hline
\end{tabular}

* $<<.0001$. 
Table 2. Comparison between left (LV) and right ventricular (RV) stroke volume (SV) measurements for both the multiple and single breath-hold $(\mathrm{BH})$ methods $(\mathrm{n}=21)$

\begin{tabular}{lccccc}
\hline & & & \multicolumn{2}{c}{ Absolute differences } \\
\cline { 5 - 6 } Parameter & LV & RV & Mean & SD & r value \\
\hline $\begin{array}{l}\text { Multiple BH } \\
\text { SV }\left(\mathrm{mL} / \mathrm{m}^{2}\right)\end{array}$ & $51 \pm 8$ & $49 \pm 8$ & -2.3 & 2.2 & $0.97^{*}$ \\
$\begin{array}{l}\text { Single } \mathrm{BH} \\
\text { SV }\left(\mathrm{mL} / \mathrm{m}^{2}\right)\end{array}$ & $52 \pm 9$ & $51 \pm 9$ & -1.4 & 4.0 & $0.90^{*}$ \\
\hline
\end{tabular}

Note: 7 subjects were excluded from this analysis as they had evidence of aortic incompetence.

end-diastole, we propose that the poorer spatial resolution means that tracing of the endocardial border for trabeculations and papillary muscles is less accurate. This is also reflected in the slight systematic underestimate of LV cardiac mass by the single breath-hold method. At end-systole, definition of the endocardial border is often easier (more accurate assessment of end-systolic volume); however, we propose that the reduced temporal resolution of the single breath-hold technique, in combination with the short systolic isovolumetric period, means that the end-systolic volume is unlikely to be measured at the smallest volume (optimal endsystolic period), resulting in an overestimation of the endsystolic volume.

Validation of real-time sequences has been performed in adults for the left ventricle during a single breath-hold and
(17) and for both ventricles in adults during free respiration (13). To our knowledge, validation of real-time single breathhold acquisition in children has not been reported previously. Furthermore, as the real-time images are retrospectively reordered into the R-R interval over which they were acquired, the images can be accepted by post-processing software as dynamic cardiac studies and can be further analyzed: an advantage over non-triggered real-time scans (13).

\subsection{Hemodynamic effects of adenosine}

We have also demonstrated the safe and successful administration of adenosine pharmacological stress to a group of children with congenital heart disease. The protocol we have used enables the effects of adenosine to be established

Table 3. Left ventricular (LV) interobserver variability data, EDV

A. Interobserver variability for the multiple breath-hold method at rest $(n=28)$

\begin{tabular}{|c|c|c|c|c|c|}
\hline \multirow[b]{2}{*}{ Parameter } & \multirow[b]{2}{*}{ Observer 1} & \multirow[b]{2}{*}{ Observer 2} & \multicolumn{3}{|c|}{ Absolute differences } \\
\hline & & & Mean & SD & $\mathrm{r}$ value \\
\hline $\operatorname{LV} \operatorname{EDV}\left(\mathrm{mL} / \mathrm{m}^{2}\right)$ & $73 \pm 17$ & $72 \pm 19$ & -2.7 & 4.2 & $0.97 *$ \\
\hline $\operatorname{LV} \operatorname{ESV}\left(\mathrm{mL} / \mathrm{m}^{2}\right)$ & $18 \pm 7$ & $18 \pm 7$ & -0.7 & 2.8 & $0.92 *$ \\
\hline $\mathrm{LV}$ mass $\left(\mathrm{g} / \mathrm{m}^{2}\right)$ & $70 \pm 22$ & $74 \pm 23$ & 4.2 & 3.7 & $0.99 *$ \\
\hline
\end{tabular}

\begin{tabular}{|c|c|c|c|c|c|}
\hline \multirow[b]{2}{*}{ Parameter } & \multirow[b]{2}{*}{ Observer 1} & \multirow[b]{2}{*}{ Observer 2} & \multicolumn{3}{|c|}{ Absolute differences } \\
\hline & & & Mean & SD & r value \\
\hline $\begin{array}{l}\operatorname{LV} \operatorname{EDV}\left(\mathrm{mL} / \mathrm{m}^{2}\right) \\
\operatorname{LV} \operatorname{ESV}\left(\mathrm{mL} / \mathrm{m}^{2}\right) \\
\operatorname{LV} \operatorname{mass}\left(\mathrm{g} / \mathrm{m}^{2}\right)\end{array}$ & $\begin{array}{l}78 \pm 17 \\
22 \pm 7 \\
67 \pm 23\end{array}$ & $\begin{array}{l}75 \pm 18 \\
19 \pm 8 \\
70 \pm 23\end{array}$ & $\begin{array}{r}-2.9 \\
-1.6 \\
2.9\end{array}$ & $\begin{array}{l}6.8 \\
3.2 \\
6.0\end{array}$ & $\begin{array}{l}0.93^{*} \\
0.91^{*} \\
0.98^{*}\end{array}$ \\
\hline \multicolumn{6}{|c|}{ C. Interobserver variability for the single breath-hold method during adenosine stress $(\mathrm{n}=17)$} \\
\hline & & & \multicolumn{3}{|c|}{ Absolute differences } \\
\hline Parameter & Observer 1 & Observer 2 & Mean & $\mathrm{SD}$ & r value \\
\hline $\begin{array}{l}\operatorname{LV} \operatorname{EDV}\left(\mathrm{mL} / \mathrm{m}^{2}\right) \\
\operatorname{LV} \operatorname{ESV}\left(\mathrm{mL} / \mathrm{m}^{2}\right)\end{array}$ & $\begin{array}{l}81 \pm 16 \\
15 \pm 8\end{array}$ & $\begin{array}{l}79 \pm 16 \\
15 \pm 7\end{array}$ & $\begin{array}{l}-2.3 \\
-0.3\end{array}$ & $\begin{array}{l}3.6 \\
2.8\end{array}$ & $\begin{array}{l}0.97^{*} \\
0.94^{*}\end{array}$ \\
\hline
\end{tabular}

$* \mathrm{p}<.0001$. 
Table 4. Changes in ventricular volume and function data measured at rest and during adenosine stress $(n=17)$

\begin{tabular}{|c|c|c|c|c|c|}
\hline Parameter & Single BH REST & Single BH STRESS & Absolute $\Delta$ & $\% \Delta$ & $\mathrm{p}$ value \\
\hline Heart rate $(\mathrm{bpm})$ & $74 \pm 14$ & $88 \pm 18$ & $14 \pm 12$ & $20 \pm 17$ & $<.001^{*}$ \\
\hline $\operatorname{LV} \operatorname{EDV}\left(\mathrm{mL} / \mathrm{m}^{2}\right)$ & $79 \pm 22$ & $82 \pm 19$ & $3 \pm 9$ & $5 \pm 12$ & .2 \\
\hline $\operatorname{LV} \operatorname{ESV}\left(\mathrm{mL} / \mathrm{m}^{2}\right)$ & $21 \pm 9$ & $17 \pm 10$ & $-4 \pm 7$ & $-19 \pm 34$ & $.03 *$ \\
\hline $\operatorname{LV~SV}\left(\mathrm{mL} / \mathrm{m}^{2}\right)$ & $59 \pm 17$ & $65 \pm 14$ & $7 \pm 8$ & $15 \pm 16$ & $.004 *$ \\
\hline LV EF (\%) & $74 \pm 8$ & $80 \pm 8$ & $6 \pm 8$ & $9 \pm 12$ & $.004^{*}$ \\
\hline $\mathrm{LV} \mathrm{CO}\left(\mathrm{L} / \mathrm{m}^{2}\right)$ & $4.2 \pm 1.4$ & $5.7 \pm 1.7$ & $1.5 \pm 1.0$ & $38 \pm 27$ & $<.001^{*}$ \\
\hline $\mathrm{RV} \operatorname{EDV}\left(\mathrm{mL} / \mathrm{m}^{2}\right)$ & $85 \pm 17$ & $87 \pm 17$ & $2 \pm 13$ & $3 \pm 14$ & .5 \\
\hline $\mathrm{RV} \operatorname{ESV}\left(\mathrm{mL} / \mathrm{m}^{2}\right)$ & $31 \pm 11$ & $25 \pm 9$ & $-6 \pm 11$ & $-12 \pm 37$ & $.03 *$ \\
\hline $\operatorname{RV~SV~}\left(\mathrm{mL} / \mathrm{m}^{2}\right)$ & $53 \pm 11$ & $62 \pm 10$ & $8 \pm 6$ & $17 \pm 14$ & $<.001 *$ \\
\hline RV EF (\%) & $63 \pm 9$ & $72 \pm 6$ & $8 \pm 10$ & $15 \pm 17$ & $<.001^{*}$ \\
\hline $\mathrm{RV} \mathrm{CO}\left(\mathrm{L} / \mathrm{m}^{2}\right)$ & $3.9 \pm 1.1$ & $5.4 \pm 1.4$ & $1.5 \pm 0.9$ & $41 \pm 28$ & $<.001 *$ \\
\hline
\end{tabular}

$\mathrm{P}$ value for paired Student t-test $(* \mathrm{p}<.05)$.

(3.5 minutes after commencing adenosine) and then sufficient time ( 2.5 minutes) to perform first pass gadolinium perfusion imaging and/or a further functional assessment under stress.

Adenosine is a potent vasodilator, and its primary use is as a stress agent in perfusion imaging for the assessment of reversible myocardial ischemia. However, there is an increase in cardiac output with the application of adenosine (3 to 104\% in our study). As expected, this was secondary to a significant increase in the heart rate $(20 \pm 17 \%)$, but we have also demonstrated a significant increase in the stroke volume $(15 \pm 15 \%)$. Increases in heart rate (18) and changes in LV ejection fraction $(19,20)$ and ventricular parameters $(21)$ have been demonstrated using nuclear scintigraphy in adults, but, to our knowledge, changes in ventricular indices during adenosine stress have not been quantified previously using MR imaging in children.

The increase in cardiac output during adenosine stress may potentially be used as a method of mimicking exercise. Assessment of changes in gradients across valvular stenosis or vascular narrowings (e.g. aortic coarctation), which may appear mild at rest, but increase significantly with an increase in cardiac output, and changes in valvular incompetence and ventricular function during stress [e.g. Tetralogy of Fallot (8)] would be possible. These MR parameters should also be assessed in conjunction with other hemodynamic parameters, including the blood pressure response. The effect of adenosine on cardiac output is not as predictable as that induced by dobutamine stress, but adenosine is a much simpler stressor to use and can easily be terminated if side effects develop.

\section{Conclusion}

Single breath-hold real-time SSFP cine imaging is robust and accurate in assessing cardiac function in children with congenital heart disease at rest and during pharmacological stress. The main advantage is that an uncooperative child need only perform one good quality breath-hold to acquire the data or, in the worse case scenario, no breath-hold without significant degradation of the image quality. During adenosine stress, there was an increase in cardiac output, secondary to an increase in both the heart rate and the stroke volume. The method may prove useful for assessing ventricular function during stress.

\section{References}

1. Kilner PJ. Adult congenital heart disease. In: Higgins CB, de Roos A, eds. Cardiovascular MRI and MRA. Philadelphia: Lippincott, Williams \& Wilkins, 2002:353-367.

2. Muthurangu V, Razavi R, Hegde SR, Taylor AM. Congenital heart disease. In: Bogaert J, Dymarkowski S, Taylor AM, eds. Clinical Cardiac MRI. Berlin: Springer, 2005:439-473.

3. Razavi RS, Hill DL, Muthurangu V, Miquel ME, Taylor AM, Kozerke $\mathrm{S}$, Baker EJ. Three-dimensional magnetic resonance imaging of congenital cardiac anomalies. Cardiol Young 2003; 13:461-465.

4. Grothues F, Smith GC, Moon JC, Bellenger NG, Collins P, Klein HU, Pennell DJ. Comparison of interstudy reproducibility of cardiovascular magnetic resonance with two-dimensional echocardiography in normal subjects and in patients with heart failure or left ventricular hypertrophy. Am J Cardiol 2002; 90:29-34.

5. Myerson SG, Montgomery HE, World MJ, Pennell DJ. Left ventricular mass: reliability of M-mode and 2-dimensional echocardiographic formulas. Hypertension 2002; 40:673-678.

6. Taylor AM, Jhooti P, Wiesmann F, Keegan J, Firmin DN, Pennell DJ. MR navigator-echo monitoring of temporal changes in diaphragm position: implications for MR coronary angiography. JMRI 1997; 7:629-636.

7. Taylor AM, Keegan J, Jhooti P, Gatehouse PD, Firmin DN, Pennell DJ. Differences between normal subjects and patients with coronary artery disease for three different MR coronary angiography respiratory suppression techniques. JMRI 1999; 9:786-793.

8. Roest AA, Helbing WA, Kunz P, van den Aardweg JG, Lamb HJ, Vliegen HW, van der Wall EE, de Roos A. Exerecise MR imaging in the assessment of pulmonary regurgitation and biventricular function in patients after tetralogy of Fallot repair. Radiology 2002; 223:204211.

9. Razavi R, Hill DL, Keevil SF, Miquel ME, Muthurangu V, Hegde S, Rhode K, Barnett M, van Vaals J, Hawkes DJ, Baker E. Cardiac catheterisation guided by MRI in children and adults with congenital heart disease. Lancet 2003; 362:1877-1882.

10. Taylor AM, Dymarkowski S, Hamaekers P, Razavi R, Gewillig M, 
Mertens L, Bogaert J. Magnetic resonance coronary angiography and late-enhancement myocardial imaging in children with arterial switch operation for transposition of the great arteries. Radiology 2005; 234:542-547.

11. Pruessmann KP, Weiger M, Scheidegger MB, Boesiger P. SENSE: sensitivity encoding for fast MRI. Magn Reson Med 1999; 42:952962.

12. Weiger M, Pruessmann KP, Boesiger P. Cardiac real-time imaging using SENSE. SENSitivity encoding scheme. Magn Reson Med 2000; 43:177-184.

13. Hori Y, Yamada N, Higashi M, Hirai N, Nakatani S. Rapid evaluation of right and left ventricular function and mass using real-time True-FISP cine MR imaging without breath-hold: comparison with segmented True-FISP cine MR imaging with breath-hold. JCMR 2003; 5:439-450.

14. Bland JM, Altman DG. Statistical methods for assessing agreement between two methods of clinical measurement. Lancet 1986; 1:307310 .

15. Moon JCC, Lorenz CH, Francis JM, Smith GC, Pennell DJ. Breathhold FLASH and FISP cardiovascular MR imaging: left ventricular volume differences and reproducibility. Radiology 2002; 223:789797.

16. Alfakih K, Plein S, Thiele H, Jones T, Ridgway JP, Sivananthan MU. Normal human left and right ventricular dimensions for MRI assessed by turbo gradient echo and steady-stae free precession imaging sequences. JMRI 2003; 17:323-329.

17. Lee VS, Resnick D, Bundy JM, Simonetti OP, Lee P, Weinreb JC. Cardiac function: MR evaluation in one breath hold with real-time true fast imaging with steady state precession. Radiology 2002; 222:835842.

18. Abidov A, Hachamovitch R, Hayes SW, Ng CK, Cohen I, Friedman JD, Germano G, Berman DS. Prognostic impact of hemodynamic response to adensoine in patients older than age 55 years undergoing vasodilator stress myoacrdial perfusion. Circulation 2003; 107:28942899.

19. Vashist A, Heller EN, Blum S, Brown EJ, Bhalodkar NC. Association of heart rate response with scan and left ventricular function on adenosine myocardial perfusion imaging. Am J Cardiol 2002; 89:174-177.

20. Fleming RM. High-dose dipyridamole and gated sestamibi SPECT imaging provide diagnostic resting and stress ejection fractions useful for predicting extent of coronary artery disease. Angiology 2002; 53:221-415.

21. Dziuk M, Canizales A, Britton KE. Left ventricular function assessed by gated SPECT after an exercise-augmented adenosine infusion. Correlation with myocardial ischaemia. Kardiol Pol 2003; 58:197206. 